\title{
EMPREGO DA ANÁLISE MULTIVARIADA NA CARACTERIZAÇÃo DE ACESSOS DE FEIJÃO (Phaseolus vulgaris L.) ${ }^{1}$
}

\author{
JAIME ROBERTO FONSECA ${ }^{2}$ E HELOISA TORRES DA SILVA ${ }^{3}$
}

\begin{abstract}
RESUMO - Com a finalidade de estudar a divergência genética e identificar possivel duplicidade em acessos de feijão, 34 materiais genéticos, disponiveis no Banco Ativo de Germoplasma da Embrapa Arroz e Feijão, foram estudados, utilizando-se dez descritores agronômicos e fenológicos, sendo os resultados obtidos submetidos a análises multivariadas. A técnica de variáveis canônicas não detectou descritores redundantes, isto é, todos foram importantes para a descrição do germoplasma. Por outro lado, a técnica de agrupamento (método do vizinho mais próximo, utilizando-se a distância generalizada $\left(\mathrm{D}^{2}\right)$ de Mahalanobis) identificou acessos repetidos de feijão nos grupos comerciais Preto e Mamoninha.
\end{abstract}

Termos para indexação: divergência genética, variáveis canônicas, distância de Mahalanobis.

\author{
USE OF MULTIVARIATE ANALYSIS IN CHARACTERIZATION \\ OF BEAN (Phaseolus vulgaris L.) ACESSIONS
}

\begin{abstract}
S - With the objective to study the genetic diversity and to identify possible repetitive acess of beans, 34 genetics samples, of the Germplasm Active Bank from National Rice and Bean Research Center (CNPAF), were studied, through ten quantitative and fenologic descriptors, submeted to multivariate analysis. The canonic variables technique determined that all traits were important for acess description. In addition, the clustering techniques (nearest neighbor method, using Mahalanobis distance) identified duplicated acessions of beans, from black and castor oilbean commercial groups.
\end{abstract}

Index terms: genetic diversity, canonic variables, Mahalanobis distance.

\section{INTRODUÇÃO}

A variabilidade genética indispensável ao melhoramento e áreas afins é tentativamente preservada em bancos de germoplasma (BAG's). Nestes, é muito freqüente a ocorrência de duplicidade de acessos, o que implica em maior tempo exigido no processo de caracterização e maior custo de manutenção e conservação do germoplasma.

Algumas metodologias têm sido utilizadas na caracterização de germoplasma, tais como o uso de isoenzimas (Brondani, 1993) e de marcadores moleculares (Maluf, 1990 e Miklas \& Kelly, 1992). Uma outra alternativa que pode ser empregada é a análise multivariada de dados morfológicos e agronômicos (Fonseca, 1993 e Ribeiro, 1993), porque além de ser a mais econômica, praticamente não exige nenhum trabalho adicional, a não ser de cálculo, uma vez que as informações para as

\footnotetext{
${ }^{1}$ Aceito para publicação em 19.11.97.

${ }^{2}$ Pesquisador, Dr., Embrapa Arroz e Feijão, Cx. Postal 179, 74001-970, Goiânia - GO.

${ }^{3}$ Pesquisador, M.Sc., Embrapa Arroz e Feijăo.
}

análises são obtidas dos próprios descritores tomados dos genótipos, o que se constitui uma atividade rotineira no BAG.

Dentre as técnicas multivariadas disponíveis, os componentes principais, as variáveis canônicas e a análise de agrupamento, a partir das distâncias de Mahalanobis $\left(\mathrm{D}^{2}\right)$, têm sido as mais usadas na avaliação da divergência genética presente em diversas espécies (Pereira, 1989; Peeters \& Martinelli, 1989; Castineiras, 1990 e Faria, 1994).

Neste trabalho, procurou-se avaliar a eficiência das técnicas multivariadas na obtenção de estimativas de divergência genética entre amostras de feijão, procedentes de coletas feitas em várias regiōes brasileiras, com os propósitos de identificar possíveis repetições de acessos e de selecionar descritores utilizados nas atividades de caracterização.

\section{MATERIAL E MÉTODOS}

O experimento foi conduzido com 34 acessos de feijão, sendo 24 do grupo Chumbinho e sete do Taquara, ambos de grão preto, e três do grupo Mamoninha, de grão rajado (Tabela 1), provenientes do Banco Ativo de Germoplasma 
TABELA 1. Grupo comercial, denominação, procedência e número dos acessos de feijão (Phaseolus vulgaris $\mathbf{L}_{\circ}$ ), caracterizados em Goiânia-GO, 1993.

\begin{tabular}{|c|c|c|c|}
\hline Número & Denominação & $\begin{array}{c}\mathrm{N}^{2} \text { de acesso no } \\
\text { BAG-Feijão-CNPAF }\end{array}$ & Procedência \\
\hline \multicolumn{4}{|c|}{ Grupo Preto Chumbinho } \\
\hline 1 & Chumbinho & 840001 & Veranópolis (RS) \\
\hline 2 & Chumbinho & 840002 & Veranópolis (RS) \\
\hline 3 & Chumbinho & 840012 & Nova Prata (RS) \\
\hline 4 & Chumbinho & 840036 & Sananduva (RS) \\
\hline 5 & Chumbinho & 840087 & Marcelino Ramos (RS) \\
\hline 6 & Chumbinho & 840095 & Erechim (RS) \\
\hline 7 & Chumbinho & 840156 & Pelotas (RS) \\
\hline 8 & Chumbinho & 800114 & Região Sul \\
\hline 9 & Chumbinho & 800162 & Regiåo Sul \\
\hline 10 & Chumbinho & 840054 & Sananduva (RS) \\
\hline 11 & Chumbinho & 830156 & Caxambú do Sul (SC) \\
\hline 12 & Chumbinho & 830167 & Palmitos (SC) \\
\hline 13 & Chumbinho & 830131 & Coronel Freitas (SC) \\
\hline 14 & Chumbinho & 840885 & Chalé (MG) \\
\hline 15 & Chumbinho & 840880 & S. José do Mantimento (MG \\
\hline 16 & Chumbinho & 840758 & Manhumirim (MG) \\
\hline 17 & Chumbinho & 840831 & Simonésia (MG) \\
\hline 18 & Chumbinho & 840844 & Simonésia (MG) \\
\hline 19 & Chumbinho & 840850 & Simonésia (MG) \\
\hline 20 & Chumbinho & 840859 & Simonésia (MG) \\
\hline 21 & Chumbinho & 840872 & Santa do Manhuacú (MG) \\
\hline 22 & Chumbinho & 840878 & S. José do Mantimento (MG \\
\hline 23 & Chumbinho & 840049 & Sananduva (RS) \\
\hline \multirow[t]{2}{*}{24} & Chumbinho & & \\
\hline & (Testemunha) & - & \\
\hline \multicolumn{4}{|c|}{ Grupo Preto Taquara } \\
\hline 1 & Taquara & 800152 & Região Sul \\
\hline 2 & Taquara & 830133 & Coronel Freitas (SC) \\
\hline 3 & Taquara & 830139 & Coronel Freitas (SC) \\
\hline 4 & Taquara & 830160 & Caxambú do Sul (SC) \\
\hline 5 & Taquara & 830164 & Caxambú do Sul (SC) \\
\hline 6 & Taquara & 830165 & Caxambú do Sul (SC) \\
\hline 7 & Taquara & 830171 & Palmitos (SC) \\
\hline \multicolumn{4}{|c|}{ Grupo Diversos (Mamoninha) } \\
\hline 1 & Mamoninha & 840471 & Barra do Mendes (BA) \\
\hline 2 & Mamoninha & 840535 & Barra do Mendes (BA) \\
\hline 3 & Mamoninha & 840536 & Barra do Mendes (BA) \\
\hline
\end{tabular}

(BAG-Feijão) do Centro Nacional de Pesquisa de Arroz e Feijão (CNPAF), da Embrapa, em Goiânia, Goiás.

Os acessos foram avaliados em julho de 1993, utilizando o delineamento experimental blocos casualizados com duas repetições, instalados em área de pesquisa do CNPAF. A semeadura foi feita manualmente em parcelas de três linhas de três metros de comprimento, distanciadas de $0,50 \mathrm{~m}$ com uma densidade de 15 sementes por metro, ou seja, 135 plantas/parcela experimental. A adubação foi realizada de acordo com a análise do solo e os demais tratos culturais foram normais à boa condução da cultura, inclusive irrigação por aspersão convencional.
Anotaram-se dados referentes a dez caracteres, sendo oito morfológicos: altura da planta (ALT), número de nós do caule principal (NNCP), comprimento do folíolo central (CFC), largura do folíolo central (LFC), comprimento da vagem (CV), largura da vagem (LV), número de sementes por vagem (NSV) e peso de 100 sementes (P100) e dois fenológicos: floração (FLOR) e ciclo cultural (CI).

Procedeu-se a análise dos dados, submetendo-os a procedimentos multivariados. Para a identificação de descritores redundantes, foi utilizada a técnica de variáveis canônicas (Rao, 1952; Bock, 1975 e Ferreira, 1993), ou seja, os caracteres que apresentavam correlações significativas com, pelo menos, uma das primeiras variáveis canônicas capazes de explicar $80 \%$ da variação total observada, foram considerados importantes. Para a quantificação da divergência genética e do agrupamento dos acessos, com vistas à identificação de duplicidades, foi utilizado o método hierárquico aglomerativo do vizinho mais próximo, adotando como medida de dissimilaridade a distância generalizada $\left(D^{2}\right)$ de Mahalanobis (Cruz, 1990; Ribeiro, 1993 e Fonseca, 1993).

\section{RESULTADOS E DISCUSSÃO}

O resumo das análises de variâncias univariadas para os dez caracteres estudados, envolvendo os 34 acessos de feijão, é indicado na Tabela 2. Constatou-se elevada precisão experimental, medida através de coeficientes de variação (variação de 2,23\% - largura da vagem até 7,52\% - altura da planta). Desse modo, foi possível detectar pelo teste $F$, diferenças significativas $(P \leq 0,01)$ para quase todos os caracteres, com exceção apenas do ciclo cultural.

Através da análise de variância multivariada obteve-se o valor da estatística de Wilks $\Lambda=7,77795$. Este valor é significa-

TABELA 2. Resumo das análises de variância univariadas de dez caracteres avaliados em trinta e quatro acessos de feijão. Goiânia-GO, 1993.

\begin{tabular}{lrrrrr}
\hline & \multicolumn{3}{c}{ Quadrados médios } & \multirow{2}{*}{ Média } & CV\% \\
\cline { 2 - 4 } & \multicolumn{1}{c}{ Blocos } & Acessos & \multicolumn{1}{c}{ Erro } & & \\
\hline ALT (cm) & 15,821 & $59,952^{* *}$ & 10,749 & 43,55 & 7,52 \\
NNCP & 8,612 & $2,750^{* *}$ & 0,442 & 16,82 & 3,95 \\
CFC (cm) & 0,016 & $0,550^{*}$ & 0,258 & 9,62 & 5,28 \\
LFC (cm) & 0,308 & $0,299^{* *}$ & 0,114 & 7,52 & 4,50 \\
CV (cm) & 0,116 & $4,262^{* *}$ & 0,077 & 10,16 & 2,74 \\
LV (mm) & 0,016 & $0,168^{* *}$ & 0,036 & 8,51 & 2,23 \\
NSV & 0,477 & $0,329^{* *}$ & 0,092 & 6,54 & 4,67 \\
P100 (g) & 2,614 & $7,074^{* *}$ & 0,503 & 17,54 & 4,04 \\
FLOR (dias) & 41,308 & $32,670^{* *}$ & 4,520 & 43,93 & 4,84 \\
CI (dias) & 3,308 & 9,098 & 10,217 & 86,75 & 3,68 \\
\hline * ** significativos pelo teste de t a 5\% e 1\% &
\end{tabular}

* $\mathrm{e}^{* *}$ significativos pelo teste de $\mathrm{t}$ a $5 \%$ e $1 \%$, respectivamente. 
tivo $(\mathrm{P} \leq 0,01)$ com 340 e 672 graus de liberdade, indicando que houve variação global entre os acessos.

Os valores característicos da análise de variáveis canônicas, obtidos da matriz de correlação dos caracteres avaliados, revelaram que as duas primeiras foram suficientes para explicar $85,5 \%$ da variação observada (Tabela 3 ), sendo que a primeira, a mais importante de todas, explicou $72,6 \%$ e a segunda, $12,9 \%$.

Os coeficientes de correlação entre os dez caracteres originais e as duas primeiras variáveis canônicas são observados na Tabela 4. Todos os caracteres foram significativos com pelo

TABELA 3. Variâncias, variâncias percentuais e acumuladas das variáveis canônicas obtidas de dez caracteres avaliados em trinta e quatro acessos de feijão. Goiânia-GO, 1993.

\begin{tabular}{cccc}
\hline \multirow{2}{*}{$\begin{array}{c}\text { Variáveis } \\
\text { canônicas }\end{array}$} & \multicolumn{3}{c}{ Variância } \\
\cline { 2 - 4 } & Variáveis canônicas & Percentual & Percentual acumulada \\
\hline 1 & 93,68011 & 72,6 & 72,6 \\
2 & 16,68942 & 12,9 & 85,5 \\
3 & 6,79593 & 5,2 & 90,7 \\
4 & 4,66740 & 3,6 & 94,3 \\
5 & 2,40571 & 1,8 & 96,1 \\
6 & 1,89405 & 1,4 & 97,5 \\
7 & 1,32055 & 1,1 & 98,6 \\
8 & 0,78686 & 0,7 & 99,3 \\
9 & 0,38719 & 0,4 & 99,7 \\
10 & 0,31222 & 0,3 & 100,0 \\
\hline
\end{tabular}

TABELA 4. Coeficientes de correlação entre os dez caracteres originais e as duas principais variáveis canônicas. Goiânia-GO, 1993.

\begin{tabular}{ccc}
\hline Caracteres originais & Variável canônica (1) & Variável canônica (2) \\
\hline ALT & $\mathbf{0 , 5 8 1 6 9 ^ { * * }}$ & 0,12516 \\
NNCP & 0,33029 & $0,84905^{* *}$ \\
CFC & $\mathbf{0 , 3 5 3 7 7 ^ { * }}$ & $-0,33692$ \\
LFC & 0,07182 & $-0,39740^{*}$ \\
CV & $-0,99531^{* *}$ & 0,03990 \\
LV & $0,69492^{* *}$ & 0,05038 \\
NSV & $0,49979^{* *}$ & $0,55577^{* *}$ \\
P100 & $-0,85909^{* *}$ & $-0,32601$ \\
FLOR & $-0,59936^{* *}$ & $\mathbf{0 , 7 6 6 4 9 * *}$ \\
CI & $0,78845^{* *}$ & $\mathbf{0 , 0 3 1 2 8}$ \\
\hline
\end{tabular}

* $\mathrm{e}^{\text {** }}$ significativos pelo teste de t a $5 \%$ e $1 \%$, respectivamente. menos uma dessas variáveis, indicando que não houve descritores redundantes, isto é, todos foram importantes na descrição dos acessos. É interessante salientàr que o ciclo cultural, que não variou significativamente entre os acessos, pode ser considerado um caráter importante na avaliação da divergência genética entre os mesmos. É provável que este fato tenha ocorrido porque essa característica não é indiretamente representada por outras e que, quando avaliada em conjunto pela análise multivariada, evidencia a sua real contribuição para a descrição, tornando-se importante, mesmo não sendo significativa na análise univariada (Ferreira, 1993; Ribeiro, 1993 e Fonseca, 1993).

O fato de não terem sido identificados caracteres redundantes entre os dez estudados, é coerente com os dados apresentados por Oliveira (1989) e Fonseca (1993) mas, discorda dos resultados de Castineiras (1990) e Faria (1994).

$\mathrm{Na}$ análise de agrupamentos, obtiveram-se dendrogramas (método hierárquico aglomerativo do vizinho mais próximo) com base nas distâncias de Mahalanobis, para os três grupos de feijão estudados.

No grupo Chumbinho (Figura 1), composto de 24 acessos, a escala apresenta uma amplitude de 0,77 , indicando uma divergência (intragrupo) maior do que nos demais, sendo possível formarem-se três subgrupos: os dois primeiros isolados formados pelos genótipos 3 e 2 , os demais constituindo o terceiro conjunto.

No grupo preto Taquara (Figura 2), constituído de sete acessos, a amplitude da divergência foi pequena $(0,20)$, sendo possivel também formarem-se três subgrupos, o primeiro isolado formado pelo acesso 4; o segundo originado pelos acessos 5 e 1, e os demais acessos constituindo o terceiro subgrupo. Finalmente, no grupo Mamoninha (Figura 3), apenas dois subgrupos foram observados: o primeiro contendo apenas o acesso 2 e o outro, os demais.

Do exposto, pela análise multivariada somente oito amostras, ao invés de 34 , deveriam ser conservadas no Banco de germoplasma. Contudo, há a possibilidade que alelos de importância dentro do grupo possam ser perdidos. Para evitar isso, sem causar maiores transtornos às atividades do Banco de germoplasma, a opção poderia ser a de fazer uma amostra composta, contendo representantes de todos os materiais coletados que foram agrupados na análise como similares. Em caso de necessidade do melhorista, durante a multiplicação desse material, poderia se identificar assim, possíveis variações úteis dentro de cada amostra. Este procedimento reduziria o custo de manutenção do Banco de germoplasma e aumentaria a eficiência no seu manuseio. 


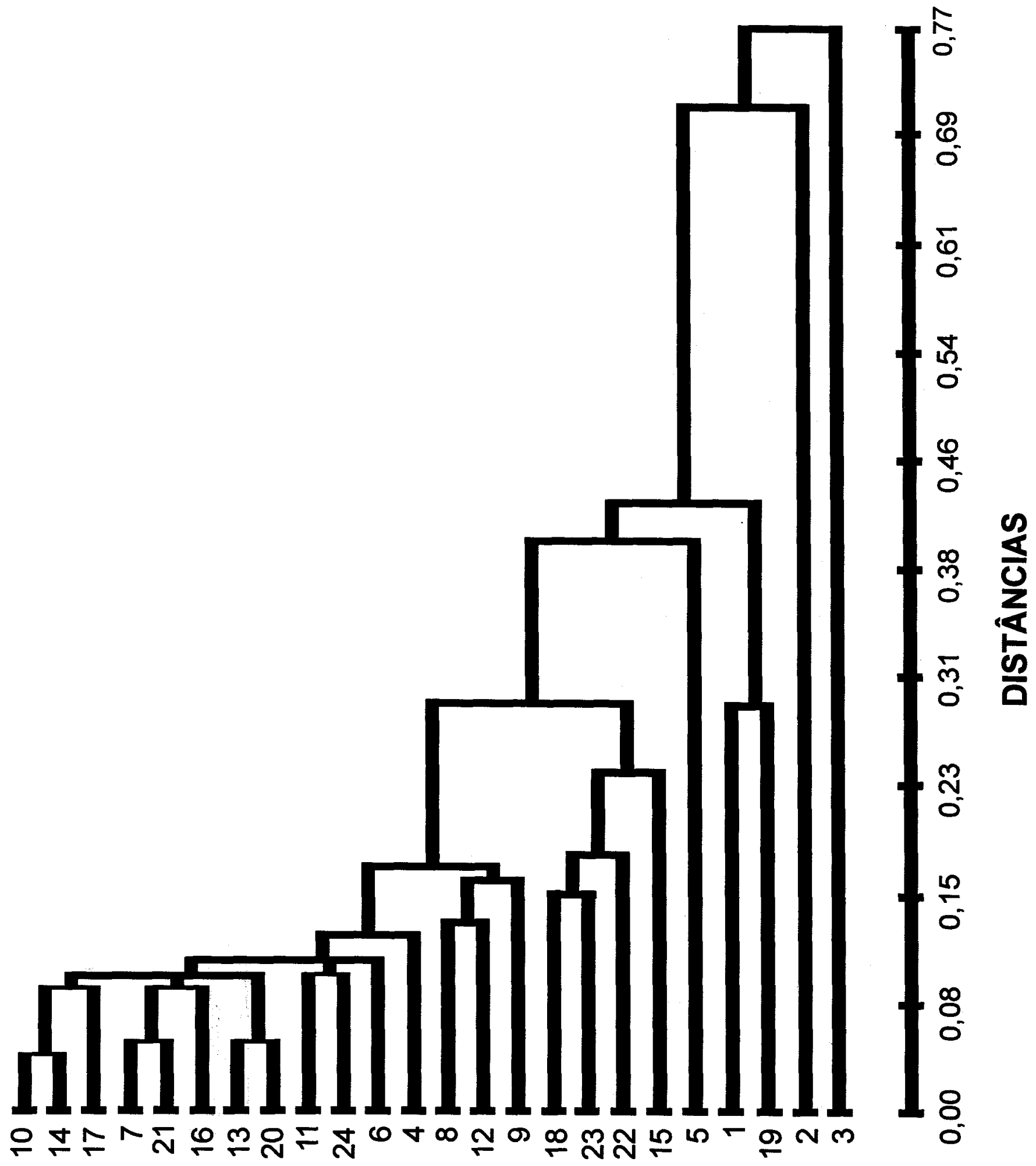

ACESSOS

FIG. 1. Dendrograma obtido pelo método hierárquico aglomerativo do vizinho mais próximo com base nas distâncias de Mahalanobis, para os 24 acessos de feijão do grupo preto Chumbinho. Goiânia-GO, 1993. 


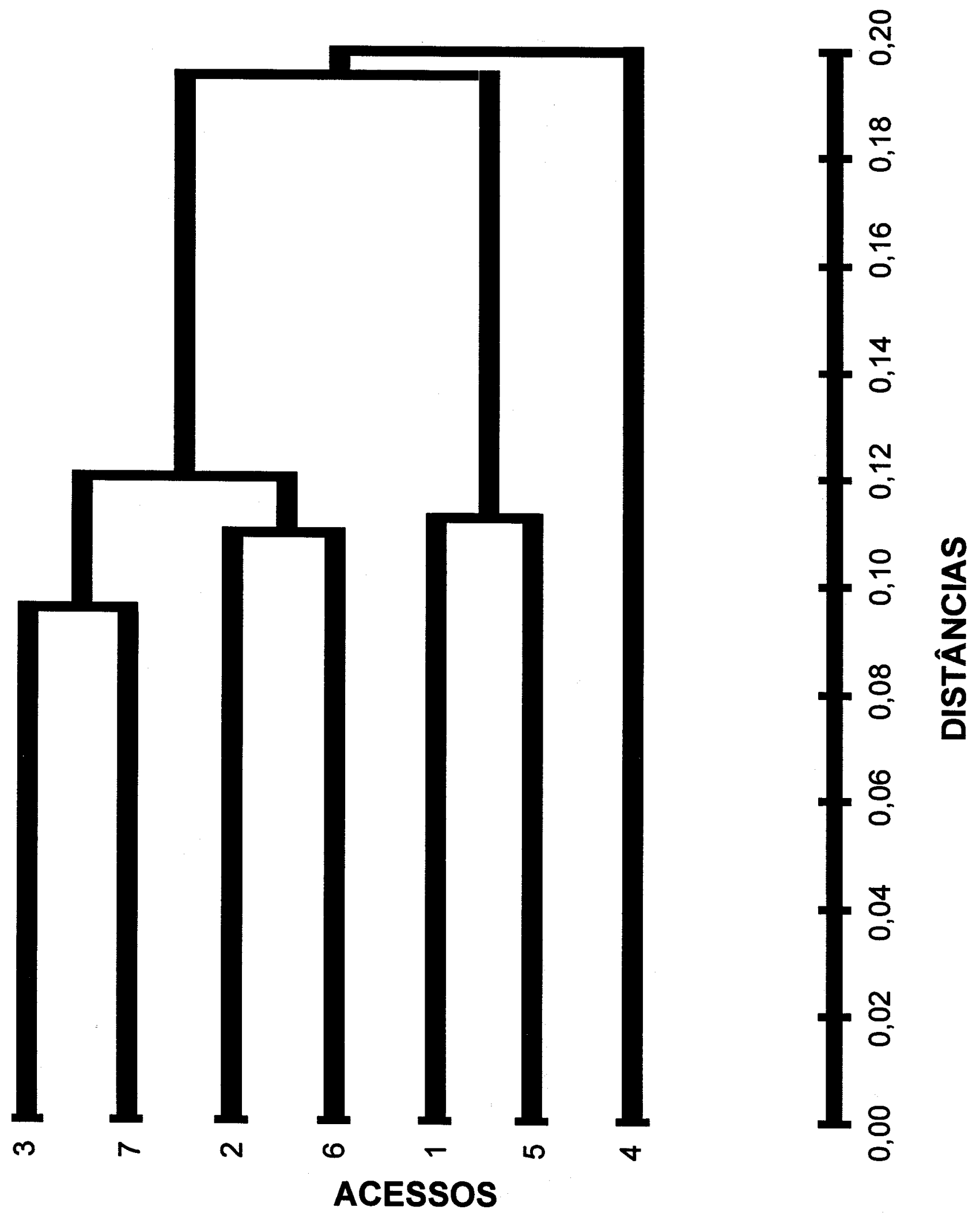

FIG. 2. Dendrograma obtido pelo método hierárquico aglomerativo do vizinho mais próximo com base nas distâncias de Mahalanobis, para os sete acessos de feijāo do grupo preto Taquara. Goiânia-GO, 1993. 

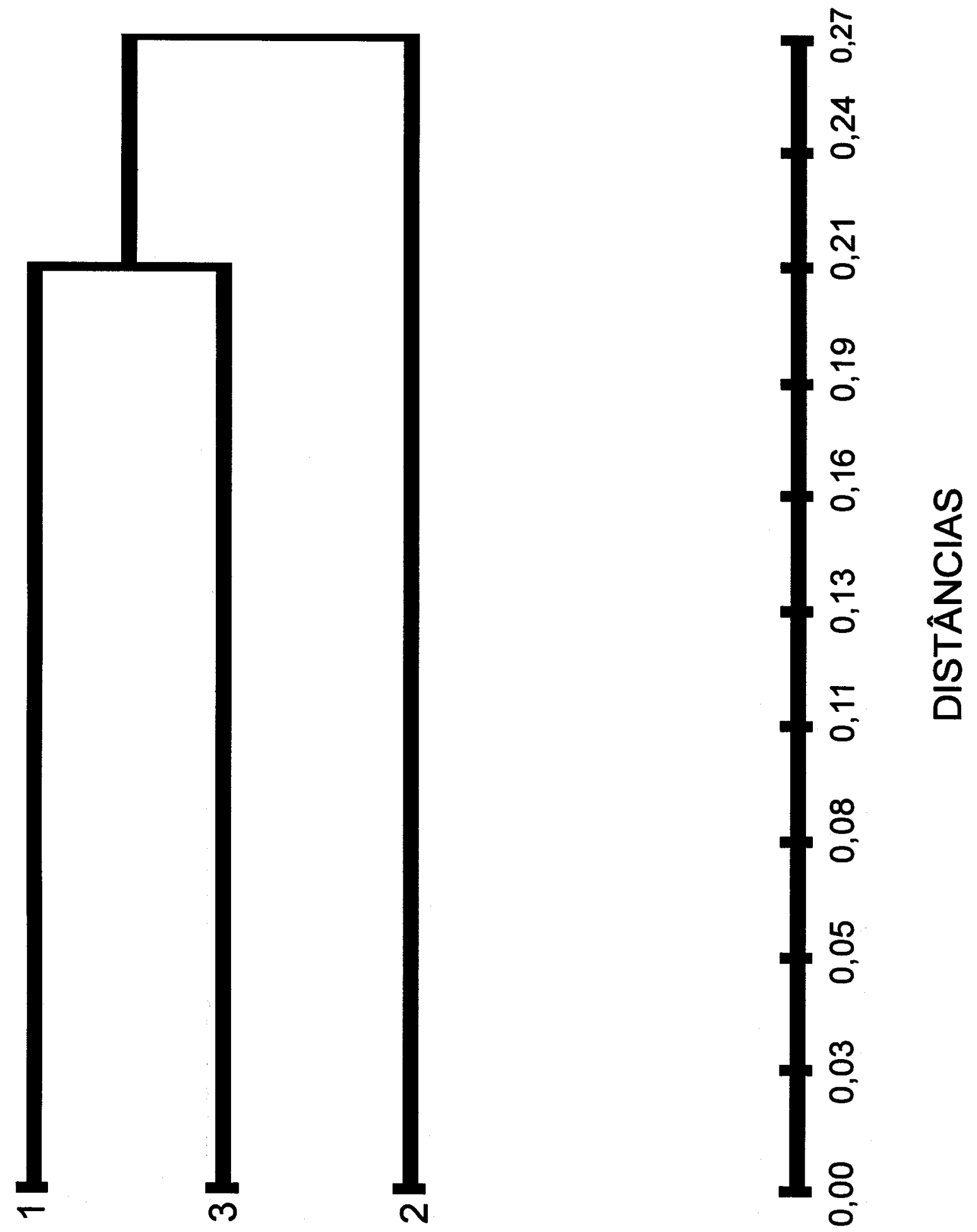

\section{ACESSOS}

FIG: 3. Dendrograma obtido pelo método hierárquico aglomerativo do vizinho mais próxim base nas distâncias de Mahalanobis, para os três acessos de feijåo do grupo Mamo Goiânia-GO, 1993. 


\section{CONCLUSÕES}

- Utilizando medidas de divergência genética, foi possível identificar acessos de feijão similares dos grupos Preto e Mamoninha, conservados na coleção do BAG/Embrapa Arroz e Feijão;

- por meio da técnica de variáveis canônicas, todos os dez descritores agronômicos e fenológicos analisados mostraramse importantes para a descrição do germoplasma.

\section{REFERÊNCIAS}

BOCK, R.D. Multivariante statistical methods in behavioral research. New York: McGraw-Hill, 1975. 623p.

BRONDANI, C. Análise de RFLP da tolerância à toxidez do alu- mínio. Lavras: ESAL, 1993. 78p. (Tese Mestrado).

CASTINEIRAS, L. Análisis de descriptores del frijol común (Phaseolus vulgaris) mediante métodos multivariados. Ciência de la Agricultura. Hawana. v.39, p.54-59. 1990.

CRUZ, C.D. Aplicação de algumas técnicas multivariadas no melhoramento de plantas. Piracicaba: ESALQ, 1990. 188p. (Tese Doutorado).

FARIA, L.C. de. Análise multivariada no estudo da divergência genética entre populações de feijăo (Phaseolus vulgaris L). do grupo mulatinho. Goiânia: UFG, 1994. 80p. (Tese Mestrado).
FERREIRA, D.F. Métodos de avaliação da divergência genética em milho e suas relaçōes com os cruzamentos dialélicos. Lavras: ESAL, 1993. 72p. (Tese Mestrado).

FONSECA, J.R. Emprego da análise multivariada na caracterização de germoplasma de feijão (Phaseolus vulgaris L.). Lavras: ESAL, 1993. 123p. (Tese Doutorado).

MALUF, W.R. Perspectivas da aplicação da biologia molecular no melhoramento de plantas: o uso dos RFLPs. In: TORRES, A.C. \& CALDAS, L.S. Técnicas e aplicações da cultura de tecidos de plantas. Brasília: Embrapa-CNPH, 1990. p.381-389.

MIKLAS, P. \& KELLY, J. Identifying bean DNA polymorphisms using the pólymerase chain reaction. In: REPORT OF THE BEAN IMPROVEMENT COOPERATIVE, 35. Anais. Fort Collins, 1992. p.21-22.

OLIVEIRA, E.J. de. Análise multivariada no estudo da divergência genética entre cultivares de feijão (Phaseolus vulgaris L.). Viçosa: UFV, 1989.91p. (Tese Mestrado).

PEETERS, J.P. \& MARTINELLI, J.A. Hierarchical cluster analysis as a tool to manage variation in germplasm collection. Theoretical and Applied Genetics, Berlin. v.78, n.1, p.42-48. 1989.

PEREIRA, A.V. Utilização de análise multivariada na caracterização de germoplasma de mandioca (Manihot esculenta Krantz). Piracicaba: ESALQ, 1989. 180p. (Tese Doutorado).

RAO, C.R. Advanced statistical methods in biometrics research. New York: John Willey \& Sons, 1952. 390p.

RIBEIRO, F.E. Divergência genética entre populações de coqueiro gigante (Cocus nucifera L.) do Brasil. Lavras: ESAL, 1993. 84p. (Tese Mestrado). 